\title{
YOUTUBERS: POTENCIAL DE CONTRIBUIÇÃO NA EDUCAÇÃO SEXUAL
}

\author{
YOUTUBERS: POTENCIAL DE CONTRIBUCIÓN SEXUAL PARA LA EDUCACIÓN
}

YOUTUBERS: CONTRIBUTION POTENTIAL FOR SEXUAL EDUCATION

\author{
Ronielisson Loiola de Jesus TAVARES ${ }^{1}$ \\ Fabiana Elias de MESQUITA ${ }^{2}$
}

\begin{abstract}
RESUMO: O presente artigo tem como objetivo apontar a viabilidade de youtubers atuarem como educadores sexuais e contribuírem na disseminação de informações em relação aos direitos sexuais e reprodutivos. A literatura vem destacando o potencial de engajamento por parte de seus seguidores em diversos comportamentos, principalmente de consumo. A mídia e estes profissionais já educam sexualmente, de maneira não formal, seu público, por meio de suas ações, temas aposentados e opiniões. Este ensaio, de natureza teórica, traz a contextualização social, exibindo ascendências e conexões deste fenômeno, através de referenciais teóricos que coadunam teorias educomunicativas, da psicanálise e teoria cognitivocomportamental.
\end{abstract}

PALAVRAS-CHAVE: Educomunicação. Youtuber. Educação sexual. Prevenção a violência sexual.

RESUMEN: Este artículo tiene como objetivo señalar la viabilidad de los youtubers para actuar como educadores sexuales y contribuir a la difusión de información sobre los derechos sexuales y reproductivos. La literatura ha destacado el potencial de participación de sus seguidores en diversos comportamientos, principalmente en el consumo. Los medios de comunicación y estos profesionales ya educan sexualmente a sus audiencias, de manera no formal, a través de sus acciones, temas y opiniones retirados.Este ensayo, de naturaleza teórica, contexto social, muestra ascendencia y conexiones de este fenómeno, a través de referencias teóricas. que coinciden con las teorías educomunicativas, el psicoanálisis y la teoría cognitivo-conductual.

PALABRAS CLAVE: Educomunicación. Youtuber. Educación sexual. Prevención a la violencia sexual.

ABSTRACT: This article aims to point out the viability of youtubers to act as sex educators and contribute to the dissemination of information regarding sexual and reproductive rights. The literature has been highlighting the potential for engagement by its followers in various

\footnotetext{
1 Universidade Estadual Paulista (UNESP), Araraquara - SP - Brasil. Mestrando em Educação Sexual no Programa de Pós-graduação em Educação Sexual. Bolsista CAPES. ORCID: https://orcid.org/0000-0003-1178910X. E-mail: ronny.tavares@gmail.com

${ }^{2}$ Universidade Presbiteriana Mackenzie, São Paulo - SP -Brasil. Mestre em Educação, Arte e História da Cultura. Universidade Presbiteriana Mackenzie. ORCID: https://orcid.org/0000-0002-1444-7749. E-mail: fabiana.mesquita@yahoo.com.br
}

RPGE- Revista on line de Política e Gestão Educacional, Araraquara, v. 24, n. 2, p. 554-570, maio/ago. 2020. e-ISSN:1519-9029. 
behaviors, mainly in consumption. The media and these professionals already sexually educate their audiences, in a non-formal way, through their actions, retired themes and opinions. that match educommunicative theories, psychoanalysis and cognitive-behavioral theory.

KEYWORDS: Educommunication. Youtuber. Sexual education. Prevention of sexual violence.

\section{Introdução}

A internet oferece uma gama de possibilidades de conteúdo. Onde antes somente havia a televisão e o rádio, como fontes de entretenimento disponíveis nos domicílios, atualmente há o Youtube, destacando-se pela grande quantidade de usuários que, independentemente da idade, acessam a plataforma em busca da diversão e/ou informação oferecidas.

Criado em 2005, (KLEINA, 2017), o Youtube constitui-se em uma plataforma interativa de compartilhamento vídeos, onde o usuário além de assistir aos vídeos, pode compartilhar e criar conteúdos audiovisuais. Globalmente, o portal possui mais de 2 bilhões de usuários conectados mensalmente, que se utilizam dos benefícios de acessarem a plataforma, seja para assistir ou divulgar conteúdos (YOUTUBE, 2019).

Semelhante a um aparelho televisivo, o site apresenta canais com os mais diversificados temas, tais como: comédia, tutoriais, educação, entretenimento, notícias, dentre outros, podendo o indivíduo mudar de canal por meio de apenas um clique, a fim de escolher o assunto desejado. De acordo com as regras de utilização do Youtube, qualquer pessoa pode postar conteúdo na plataforma, seja ela, pessoa física, jurídica ou órgãos governamentais (PRIOSTE, 2016).

Quando uma pessoa física cria um canal e desenvolve conteúdo com certa frequência é chamada de youtuber. Motta, Bittencourt e Viana, (2014, p. 4) conceituam o termo como: o indivíduo que "posta vídeos de acordo com a frequência que lhe convém, e seu conteúdo pode ser assistido por qualquer internauta que encontre seus vídeos através de pesquisa [...]”.

A interação singular entre o usuário e o produtor de conteúdo é única, tendo em vista que cada proprietário de canal desenvolve uma postura, linguagem e material próprios, focado no perfil do seu público-alvo para, assim, conseguir alcançar milhares de visualizações e seguidores.

Entre os diversos donos de canais que postam conteúdos com frequência na plataforma, alguns destacam-se por seu conteúdo e quantidade de seguidores, alcançando o nível de viver da renda oriunda de seu trabalho virtual. Entre junho de 2018 a junho de 2019, os dez maiores proprietários de canais no Youtube arrecadaram cerca de US\$ 162 milhões de dólares (BERG, 2019), através da monetização de seus vídeos. 
O Youtube é uma ferramenta de entretenimento e informação, mas também atua como instrumento de influência de comportamentos dos jovens, inspirados por seus ídolos virtuais. Westenberg (2016) aponta que crianças e adolescentes imitam sinais, piadas, e até a maneira de se comunicar que consideram interessantes, mesmo quando desaprovadas por seus pais. Não por acaso os youtubers são chamados também de influenciadores digitais. Eles se destacam por se tornarem referência, seja por meio de suas opiniões, ações ou estilo de vida, ou por poderem induzir decisões de seu público em termos de consumo e comportamento (KARHAWI, 2017).

Essa capacidade de influência pode ocorrer de maneira direta, ao induzirem a opinião do espectador, através de testemunhais direcionados a promoção de algum produto, ou mesmo demandar que determinadas ações sejam realizadas, o que pode acontecer de maneira indireta, através de merchandising, uso de determinada marca de vestuário, eletrônicos ou cosméticos, por exemplo, ou mesmo através da demonstração/divulgação de determinado produto através do canal.

Os youtubers tornaram-se referência não só para crianças e jovens em relação ao seu comportamento e atitudes, com isso em mente, seria possível estes profissionais atuarem como fonte informação em relação a temas ligados à sexualidade e a educação sexual? É possível que a educação sexual possa ser realizada no ambiente virtual e, assim, alcançar um maior número de indivíduos?

Este ensaio, de natureza teórica, tem como objetivo discorrer sobre o potencial de engajamento de youtubers no comportamento, principalmente, de adolescentes e crianças e refletir sobre como estes profissionais podem contribuir na discussão de temas relacionados à educação sexual. Dividido em três seções, inicia a discussão sobre o poder dos criadores de conteúdo do Youtube em incentivar condutas de crianças e, posteriormente, discorre sobre a educação sexual e seus fundamentos, finalizando acerca da importância de inserir estes profissionais na educação sexual.

\section{O poder de Youtubers para instigar comportamentos}

$\mathrm{O}$ uso da internet vem aumentando anualmente, principalmente com as crianças, adolescentes e pessoas acima de 45 anos que tem como principal atividade assistir vídeos e filmes online (CENTRO REGIONAL DE ESTUDOS PARA O DESENVOLVIMENTO DA SOCIEDADE DA INFORMAÇÃO, 2018; INSTITUTO BRASILEIRO DE GEOGRAFIA E ESTATÍSTICA, 2018). 
A interação com as mídias digitais não ocorre mais de forma passiva, com o sujeito apenas recebendo a informação. As novas tecnologias vêm contribuindo na produção e disseminação de conhecimentos e informações (SANTOS, 2017), nas quais o indivíduo encontra uma gama de possibilidades de aprendizagem de diversos conteúdos.

A interação se tornou o cerne das relações sociais, onde o indivíduo constrói sua imagem no mundo real e virtual. Guedes Vieira e Calazans (2017) apontam que a fabricação da imagem construída no mundo virtual, consiste no agrupamento de padrões e individualismos, de modo que a imagem é construída sobre o olhar do outro, transformando a vida privada em um espetáculo. Ou seja, no mundo virtual é possível construir uma imagem de si por meio da aplicação de padrões comportamentais que podem ser tipificados, por meio da variedade de fotos e comentários postados, que obedecem um padrão no intento de estabelecer uma imagem positiva focada no espectador e visando causar uma boa impressão.

No caso do Youtube, o objetivo dos criadores de canais, não consiste apenas em entreter, mas em gerar um conteúdo que agrade e estimule o telespectador a continuar consumindo o material oferecido, recompensando o produtor por meio do engajamento e visualizações desse canal. A relação de influência entre consumidor e produtor é uma via de mão dupla, tendo em vista que o youtuber produz os vídeos objetivando agradar seu público e este comenta, aprovando ou não o conteúdo, dando pistas sobre qual caminho deva ser seguido. Quanto mais visualizações e engajamentos, maior o prestígio do canal.

A Teoria da Social Cognitiva, desenvolvida por Alfred Bandura, com a contribuição de outros pesquisadores, concebe que o comportamento humano está enraizado em sistemas sociais, nos quais o ambiente, fatores particulares e comportamentais individuais, influenciariam essa relação de forma bidirecional (BANDURA, 1986; 2008). De acordo com o autor, é possível que o indivíduo aprenda novos comportamentos por meio da imitação, conceituada como "tendência de uma pessoa para emitir comportamentos ou atitudes similares àqueles exibidos por modelos reais ou simbólicos" (BANDURA, 1962 apud COSTA, 2008, p. 128). A aprendizagem pode ocorrer por meio da observação de comportamentos realizados por outra pessoa ou por meio simbólico através de vídeo ou mídia eletrônica, conhecido como modelação (BANDURA, 2008). Este processo de aprendizado do sujeito, ocorre em todo processo de desenvolvimento, da infância até a fase adulta, principalmente em comportamentos operacionais, em que o indivíduo aprende a realizar determinados comandos. Os pais e o ambiente familiar constituem-se como os principais modelos comportamentais para a aprendizagem de condutas. 
A teoria social cognitiva apresenta evidências sobre o motivo de youtubers influenciarem o comportamento de seus inscritos, principalmente o de crianças que, antes dos 12 anos, ainda não possuem autonomia intelectual e moral. Neste período, ela tende a acreditar que as afirmações de figuras de autoridade e prestígio são intrinsicamente verdadeiras (SILVA; SANTOS, 2019).

As crianças e adolescentes utilizam as mídias para a interação com seus pares, produzindo conteúdos e sentidos, construindo esta sociabilidade em rede, na qual se submetem, por meio da interação em torno de temas de interesse comum, ou através de grupos formados por afinidades. Uma forma de socialização, ocorre por meio das interações com os próprios youtubers, que compartilham seu cotidiano, preferências de consumo, opiniões dos mais variados temas e a interação realizada por meio de comentários e, assim, cria-se uma relação de proximidade. Relação esta que embasa o conteúdo publicitário, realizado em forma de diálogo e opiniões, geralmente positivas, sobre o produto apresentado.

O poder de influência de vídeos disponibilizados nas redes sociais ao se realizar atos, sejam eles benéficos ou prejudiciais, é inegável. O desafio "Desafio do Balde de Gelo" (Ice Bucket Challenge, em inglês), iniciado em 2014 como estratégia para angariar fundos para uma pesquisa sobre a Esclerose Lateral Amiotrófica (ELA) arrecadou 220 milhões de dólares (REUTERS, 2019).

Já um exemplo mais recente e nada positivo, do poder de "viralização" de conceitos e atos, foi o "desafio da rasteira" ou "quebra crânio". Através de um desafio postado no Instagram e Tik Tok, e largamente compartilhado por grupos de WhatsApp, por conta do Youtuber Robson Calabianqui, conhecido nas redes sociais como "Fuinha", uma brincadeira, de consequências possivelmente fatais, começou a se espalhar por ambientes infantis e juvenis, levando muitas crianças e adolescentes à hospitalização.

A postagem de Fuinha consistiu em um vídeo no qual ele e seu irmão golpeiam sua mãe com uma rasteira dupla, derrubando-a violentamente ao chão. O "desafio" viralizou e muitos jovens passaram a postar em suas redes a replicação do golpe, que pode ser fatal. A rasteira é dada no colega, quando este está em pleno ar e indivíduo cai de costas e normalmente bate a cabeça no chão (COSTA, 2020). O golpe pode causar traumatismo craniano e levar à morte, como ocorreu com uma jovem de 16 anos do Rio Grande do Norte (ESTADO DE MINAS, 2020). 


\section{Educação sexual: conceito e fundamentos}

Desde o nascimento a criança é orientada em relação a determinados comportamentos de gênero, tais como brincadeiras e cores de roupas, o uso dos genitais para distinguir menina e menino entre outros, este processo é denominado educação sexual. Ribeiro (1990, p. 2-3) descreve que a educação sexual:

Refere-se aos processos culturais contínuos desde o nascimento que, de uma forma ou de outra, direcionam os indivíduos para diferentes atitudes e comportamentos ligados à manifestação da sexualidade. Esta educação sexual é dada sem uma metodologia, um programa ou preocupação escolar e didática, mas ocorre na família, no bairro, com amigos, pela TV, pelas revistas e até na escola, transmitindo valores e determinados padrões sexuais da época.

Essa educação sexual tem caráter não-intencional, sendo realizada, incialmente pela família, depois por pares e grupos sociais, ao ser objeto de ensino com método, objetivo, organização, didática e a formação e preparação do profissional executar a ação, torna-se formal (MAIA; RIBEIRO, 2011).

Furlani (2013),descreve que o papel da educação sexual consiste em problematizar as "verdades únicas" e modelos hegemônicos da sexualidade considerada normal e, assim, questionar sobre os interesses envolvidos neste jogo de poderes para que se possa apresentar a múltiplas possibilidades relacionadas ao desejo sexual, bem como discutir sobre a exclusão das diferentes

Maia e Ribeiro (2011) complementam que a educação sexual deve ter como foco ir além dos temas tradicionais e conhecidos, não se resumindo ao compartilhamento de conceitos referentes às Infecções Sexualmente Transmissíveis (IST) ou de gravidez na adolescência, até porque, esses temas são geralmente ministrados por uma ótica médica e higienista focada, primordialmente, em doenças e estratégias de prevenção, mas temas como: violência sexual, sexualidade das pessoas com deficiência ou doenças crônicas, terceira idade, equidade de gênero, entre outros, são alguns dos diversos tópicos que os educadores sexuais podem e devem atuar.

Para que possa executar um trabalho de forma intencional, é fundamental que o profissional tenha formação na área da sexualidade, por meio de formação acadêmica. A qualificação pode ser realizada de maneira presencial ou online, através de cursos de formação e pós-graduação focados na área da sexualidade e educação sexual (LEMES; MAIA; REISYAMAUTI, 2015). 
A capacitação do profissional, independentemente do local de atuação, torna-se essencial para que se possa ministrar o conteúdo embasado cientificamente (MAIA; RIBEIRO, 2011), de forma a evitar as seguintes atitudes prejudiciais, descritas por Maia (2004): a) atitude conservadora, quando o profissional tende a abandonar a discussão por considerar o tema delicado e complexo; b) propostas reprodutivistas e superficiais, quando se reproduz o que se sabe sem agregar conteúdo; c) entusiasta e exagerada, quando a responsabilidade e reflexão são deixadas de lado, focando somente no prazer; d) postura moralista, quando as informações não são embasadas cientificamente e baseadas nas concepções pessoais e moralistas.

A educação sexual atua como ferramenta na promoção da saúde sexual e reprodutiva dos sujeitos, por meio do acesso à informação dos direitos sexuais e reprodutivos dos indivíduos, caracterizando-se por termos conceituados na Conferência Internacional sobre População e Desenvolvimento (CIPD), em 1994 como:

Estado de completo bem-estar físico, mental e social e não simples a ausência de doença ou enfermidade, em todas as matérias concernentes ao sistema reprodutivo e a suas funções e processos [...]. Isto inclui também a saúde sexual cuja finalidade é a intensificação das relações vitais e pessoais e não simples aconselhamento e assistência relativos à reprodução e a doenças sexualmente transmissíveis (ONU, 1994, p. 62).

O documento acima complementa que os níveis insuficientes de informação sobre sexualidade, serviços inadequados, comportamento sexual de alto risco e atos discriminatórios são fatores determinantes para a frustração na saúde reprodutiva de adolescentes, que são os mais prejudicados pela ausência de informação e por serviços de saúde que não contemplam as suas especificidades.

Ações educativas focadas na sexualidade devem debater crenças e tabus que afetem a saúde sexual e reprodutiva dos indivíduos. Ao afirmar que o melhor momento para a sua relação sexual é quando se sentir preparado, a importância de se usar métodos preventivos mesmo na primeira relação e que é direito do indivíduo o acesso à informação sobre os métodos contraceptivos e preventivos, bem como a escolha do insumo que se adapte às suas necessidades, são formas apresentar os direitos sexuais e reprodutivos (ONU, 1994).

\section{Por que e como inserir os Youtubers na Educação Sexual?}

Os conteúdos midiáticos exercem uma educação sexual de maneira não intencional com os seus telespectadores, seja ao utilizar cores ou objetos específicos, para apresentar associações baseadas em gênero, por exemplo: Homens e carros, cervejas, mulheres e cuidado do lar, beleza 
e moda, ou até utilizando artifícios de apelo sexual. Cecarello (2016, p. 176), descreve que "os conteúdos podem apresentar nudez (geralmente feminina), comportamentos sexuais provocativos, beleza física e emprego de simbologias sexuais". Se os conteúdos midiáticos "educam" sexualmente de maneira informal, utilizando recursos diversos, podemos e devemos ocupar estes espaços para realizar educação sexual de maneira adequada e intencional.

O uso da internet vem aumentando anualmente e seus usuários a utilizam com fins diversos (INSTITUTO BRASILEIRO DE GEOGRAFIA E ESTATÍSTICA, 2018). Por ser uma ferramenta gratuita, necessitando apenas de um dispositivo de tela e do acesso à internet, bem como de apresentar conteúdo diversificado, os usuários, com idades variadas, utilizam o Youtube cada vez mais, alcançando bilhões de usuários acessando mensalmente. É essencial que educadores em geral venham a ocupar este espaço, transmitir o conteúdo em locais que as vias tradicionais e as ações presenciais não alcançam o público-alvo. Seja por meio de canais criados pelos educadores ou realizando parcerias e consultorias.

Por utilizar informação simples e diretas existe uma redução de barreiras entre o profissional e o público, os criadores de conteúdo do Youtube conseguem atrair um grande público. Os profissionais que tratam exclusivamente da temática em seus canais conseguem desmistificar alguns tabus e esclarecer dúvidas, que o grande público muitas vezes não consegue expressar a um profissional pessoalmente, por culpa ou receio.

Percebendo a necessidade de inserir a temática da prevenção ao HIV/Aids, que não se consegue por meio dos métodos tradicionais, principalmente aos jovens, e promover o debate em relação à prevenção, o Programa Conjunto das Nações Unidas sobre HIV/Aids no Brasil (UNAIDS) percebeu o potencial dos profissionais que desenvolvem conteúdo de mídia online e em 2018, convidou youtubers brasileiros a participarem do "Desafio UNAIDS". O desafio consistiu em convidar os influenciadores a responderem perguntas acerca da temática, produzindo conteúdo em seus canais relacionados a temática do HIV, no intento de promover o engajamento entre os produtores de conteúdo e seus fãs no ambiente virtual (Programa Conjunto das Nações Unidas sobre HIV/Aids no Brasil-UNAIDS, 2018).

Especialistas na área de sexualidade que possuem canais no Youtube, por meio de seus vídeos, realizam a educação sexual de maneiras diversas, seja respondendo perguntas ou com conteúdo específico. A título de exemplo, a uroginecologista e especialista em sexualidade feminina, Cátia Damasceno, em seu canal "Mulher bem resolvida" possui aproximadamente seis milhões de inscritos e com vídeos com mais de nove milhões de visualizações; A psicóloga e sexóloga Carla Cecarello, por meio do seu canal de mesmo nome, possui vídeos com milhares de visualizações e inscritos, nos quais discute uma infinidade de temas, desde respostas a 
perguntas e apresentação de conteúdos com a proposta de discussão de temas, como "Educação Sexual", onde a profissional convida a reflexão sobre a educação sexual no ambiente escolar.

Também o fazem o médico infectologista Marcos Vinicius Almeida, voltado principalmente à população LGBTQI+ e João Geraldo Netto, que como outros youtubers que vivem com HIV, exploram temas específicos, focando primordialmente na vivência e nas especificidades deste público, por meio de conteúdo informativo e compartilhamento de seu cotidiano, como pessoa vivendo com HIV/Aids, quebram diversos tabus relacionados a sorologia positiva e a vivência pós diagnóstico.

Além dos profissionais, que já realizam a educação sexual, alguns youtubers, possuem canais específicos, com o conteúdo e público delimitados nessa área de atuação, e poderiam eventualmente contribuir no processo de educação sexual não formal, por meio de ações educomunicativas pontuais, em datas específicas ou pontuando temas em sua discussão. As ações baseadas na edoucomunicação, ao atuarem na interface entre a comunicação e educação (MARQUES; BORGES, 2016) auxilia, por meio das mídias, no processo de instrução do indivíduo e pensamento reflexivo, não só em relação ao uso das mídias, mas de temas que necessitam de diálogo, como no caso da utilização dos meios de comunicação para a discussão acerca da educação sexual.

Nichos em que as formas tradicionais de ensino realizadas pelos educadores sexuais tem dificuldades de inserir as discussões, como crianças e idosos, podem contribuir pautando temas específicos e pontuais relativos a necessidade de informação de cada faixa etária, conforme apresentamos a seguir, algumas sugestões de temas e público-alvo que podem ser abordados por meio de ações no Youtube de maneira sucinta e sem esgotar a literatura.

\section{A educação sexual com crianças}

A criança desde sua mais tenra idade manifesta sua sexualidade, iniciado por meio da autodescoberta do corpo, através da curiosidade e da automanipulação. Freud demonstrou que a sexualidade não é como um interruptor que é acionado na adolescência e que a criança é assexuada e, sim, que a sexualidade constitui-se, de forma processual, em três fases: oral, anal e fálica e genital, "que vão culminar na vida sexual adulta, em que as pulsões, antes parciais, ficarão sob o domínio da zona genital” (COUTO, 2017, p. 1).

É costume ao conversar com crianças sobre o corpo e sua sexualidade, que eufemismos em relação aos órgãos genitais (MONTEIRO; STORTO, 2019) contribuam no desconhecimento das crianças em relação ao próprio corpo, pois os pais ao temerem ou 
desconheceram a terminologia científica utilizam os termos como para nomear de forma velada, sem aprofundar-se no tema da sexualidade.

O ambiente escolar não está imune à sexualidade, pois com o convívio e nas diferenças também se aprende, ocorre a construção da sexualidade de crianças por meio das relações com seus pares, adultos e conteúdos midiáticos disponibilizados pela escola e família. A criança, de maneira indireta, recebe uma educação sexual por meio dos conteúdos midiáticos dirigidos a elas, nos quais os comportamentos dos personagens apresentam valores ideológicos (PACHECO; MELO, 2015).

Conforme descrito por Brancaleoni e Oliveira, (2015), o discurso de que a sexualidade inicia-se somente na adolescência não ocorre somente com os pais, mas os professores também apresentam tal concepção. Ao não conceber a criança como um ser sexual impede-se que ela possua o acesso as informações básicas sobre seu corpo.

Spaziani e Maia (2015) afirmam que o discurso hegemônico de que a criança é assexuada e, portanto, não necessita de educação em relação a sua sexualidade, é fator que contribui na desinformação em relação a seus direitos. A educação sexual constitui-se como uma ferramenta de prevenção, para que a crianças possam discernir os atos de carinho com situações de violência, assegurar o seu direito de negar toques e situações que considere desagradáveis, bem como a quem solicitar ajuda.

A violência sexual contra crianças e adolescentes consiste em uma violência que agride os direitos das vítimas, o indivíduo mais velho, podendo ser homem ou mulher se aproveita do desconhecimento para sua satisfação sexual, conceituada como a

Solicitação sexual indesejada e inadequada ou exposição a uma criança por uma pessoa mais velha (abuso sem contato), toque ou afago genital (abuso de contato) e penetração em termos de relações orais, anal ou vaginal ou tentativa de relação sexual (ANDREWS et al., 2004, p. 1853-1854).

A prevenção à violência sexual por meio da ação dos youtubers pode contribuir na redução dos percentuais nacionais. Entre 2011 e 2017, foram notificados no Sistema Nacional de Agravos e Notificação (SINAN) 184.524 casos de violência sexual, os casos relacionados à crianças e adolescentes corresponderam por 46,5\% (BRASIL, 2018).

As ações a serem realizadas podem ser mais simples, por exemplo, discorrer sobre o direito da criança de recusar um abraço ou beijo, ou mais elaboradas, ao dedicar um vídeo para explanar, de maneira detalhista, sobre como diferenciar toque de carinho de um toque abusivo. Como a maioria dos principais canais é produzido por crianças e para crianças, utilizando sua linguagem, o conteúdo, sob supervisão adequada e com conteúdo adaptado e específico para 
cada tema, tem potencial de alcançar um público que as ações tradicionais não conseguem, principalmente pelo alcance dos influenciadores mirins que possuem milhões de seguidores.

\section{Pessoa com deficiência}

As representações em relação à pessoa com deficiência vem se modificando, principalmente em relação à deficiência intelectual, que além de segregação limitava suas potencialidades (CARNEIRO; COSTA, 2017), principalmente em relação à sua sexualidade.

A sexualidade da pessoa com deficiência é um tema invisibilizado nas discussões midiáticas, sendo sua presença ínfima, ao se comparar os temas mais frequentes relacionados aos estudos da sexologia. Esta população, geralmente é concebida como assexuada ou sem possibilidade de ter um relacionamento amoroso, principalmente, com pessoas que não possuem algum tipo de deficiência (SOUZA; DENARI; COSTA, 2017).

Maia et al., (2015), constataram por meio da aplicação de um programa de intervenção focado nas pessoas com deficiência intelectual, que os participantes, apesar de desconhecer os conceitos de sexualidade, educação sexual e temas relacionados à prevenção às IST, vivenciam sua sexualidade como qualquer indivíduo, entretanto, tendem a ser vigiados e monitorados por um adulto sem deficiência.

Os pais e responsáveis devem participar do processo educativo, para quebrar seus tabus em relação à sexualidade, e mudar seus comportamentos e crenças relacionados à sexualidade de seus filhos (ALBUQUERQUE, 2011), para assim educa-los de maneira emancipatória para que sejam capazes de exercer seus direitos.

Sendo assim, a discussão na mídia deve ter como protagonista quem vive a realidade e expor sob sua ótica os preconceitos vividos para que o público possa compreender que o sexo é realizado normalmente, apenas com as adaptações necessárias para a deficiência possuída, destacando que cada indivíduo tem as suas particularidades.

\section{Terceira idade}

A sociedade estabelece normas em relação aos comportamentos e, no caso da sexualidade, dita os direitos e deveres, permissões atribuídas a cada faixa etária, sendo os idosos os mais podados em relação aos seus direitos sexuais (FRUGOLI; MAGALHÃES JÚNIOR, 2011). 
Apesar da crença de que o idoso é assexuado ou deva abdicar do seu desejo em função de sua idade, esta população mantém-se ativa sexualmente. A última 'Pesquisa de Conhecimento Atitudes e Práticas na População Brasileira' (BRASIL, 2018), encontrou um percentual de $71,5 \%$ de indivíduos com idade entre 45 a 64 anos que tiveram relações sexuais nos últimos 12 meses da realização da pesquisa e que 20,4\%, da população com a mesma faixa etária, utilizou preservativo em sua última relação sexual. Outro dado que aponta que os idosos estão cada vez mais ativos sexualmente são os percentuais de diagnóstico de HIV em indivíduos com idade acima de 50 anos, especialmente ao se comparar os percentuais entre 2008 e 2018 de indivíduos com a faixa etária entre 55 a 59 anos e acima de 60 anos, que mostrou aumento, de respectivamente, $69 \%$ e $85 \%$.

Os padrões de beleza são focados na juventude, e tem-se que alterações fisiológicas decorrentes da idade, comorbidades e necessidade de medicamentos são alguns fatores que influenciam no desejo sexual das pessoas com idade mais avançada (ALENCAR et al., 2014). A educação sexual auxilia o idoso a conhecer sobre seu corpo, as mudanças físicas e o desejo decorrentes desta fase, para que possa manter e alcançar a atividade sexual, consigo mesmo e com seus parceiros, de maneira satisfatória e benéfica tanto para homens e mulheres, pois sua sexualidade é punida por preconceitos (FUGOLLI; MAGALHÃES JÚNIOR, 2011), chegando ao ponto de ao idoso ativo sexualmente serem atribuídos adjetivos pejorativos.

Os idosos vêm ocupando cada vez mais espaço como protagonistas na sociedade e nas redes sociais. Os influenciadores digitais da terceira idade não seguem os padrões adotados pelos jovens em relação ao comportamento e conteúdo de mídia. Em relação a este público, destacamos a empresária e influenciadora estadunidense, Iris Apfel, a nonagenária, considerada ícone de estilo e uma das poucas pessoas vivas e não designer a ter seu acervo exposto no Metropolitan Museum of Art (L'OFFICEL, 2019). O canal brasileiro avós da razão, apresentado por três senhoras com 77, 82 e 91 anos, abordam temas diversos em seus vídeos, inclusive a sexualidade e, por meio dos conteúdos abordados, buscam reduzir o preconceito com a pessoa idosa (AVÓS DA RAZÃO, 2019).

\section{Considerações finais}

Os influenciadores digitais têm grande poder para induzir o comportamento dos indivíduos, realizando de maneira indireta ações que possam estimular determinados comportamentos, utilizando diversas ferramentas para promover o engajamento de seus seguidores. 
Este potencial, de estimular a participação, pode ser utilizado para a promoção da educação sexual e disseminação de informações que possam contribuir na saúde sexual e reprodutiva dos indivíduos. A ação sexual pode ser realizada por meio das mídias, para que possa atingir o maior quantitativo de indivíduos e alcançar localidades que as ações presenciais têm dificuldade em alcançar.

Os produtores de mídia que atuam no Youtube podem contribuir por meio de ações educominicativas pontuais ou contínuas, por meio de capacitação ou apoio de profissionais especialistas em sexualidade, para se determinar o público-alvo e o conteúdo mais adequado a ser ministrado.

Pelo fato de a sexualidade ser um processo que inicia em tenra idade e continua durante todo o desenvolvimento do indivíduo, as ações podem abranger todos os públicos e faixas etárias, as especificidades de cada público, como a população LBGT, crianças, entre outras, podem ser debatidas utilizando as datas comemorativas, como o dia nacional de combate ao abuso e à exploração sexual de crianças e adolescentes, celebrado em 18 de maio.

Este trabalho ao contribuir na discussão sobre a possibilidade de se realizar ações educativas com a contribuição dos youtubers, pode estimular pesquisas empíricas que abordem tanto o poder de influência destes profissionais quanto o poder de influência em relação a informações e comportamentos relacionados à sexualidade.

AGRADECIMENTOS: O presente trabalho foi realizado com apoio da Coordenação de Aperfeiçoamento de Pessoal de Nível Superior Brasil (CAPES) - Código de Financiamento 001.

\section{REFERÊNCIAS}

ALBUQUERQUE, P. P. Sexualidade e deficiência intelectual: Um curso de capacitação para pais. Psicologia Argumento, [s. 1.], v. 29, n. 64, p. 109-119, jan./mar. 2017. Disponível em: https://periodicos.pucpr.br/index.php/psicologiaargumento/article/view/20389/19653. Acesso em: 04 maio 2020.

ANDREWS, G. et al. Child sexual abuse In: EZZATI, M. et al. (Eds.). Comparative Quantification of Health Risks: Global and Regional Burden of Disease Attributable to Selected Major Risk Factors. v. 2. Geneva, Switzerland: World Health Organization, p. 18511940, 2004.

APRESENTAÇÃO das avós da razão. [S. l.: s. n.], 1 vídeo (2 min). Publicado pelo canal Avós da Razão. Disponível em: https://www.youtube.com/channel/UCPaLH5sjIoxe6Cm11lYtjA. Acesso em: 04 maio 2020. 
BANDURA, A. Social foundations of thought and action: a social cognitive theory. Englewood Cliffs, NJ: Prentice-Hall. 1986.

BANDURA, A. A evolução da teoria social cognitiva. In: BANDURA, A.; AZZI, R. G.; POLYDORO, S. (Orgs.). Teoria social cognitiva: conceitos básicos. Porto Alegre: Artmed, p. 15-41, 2008.

BERG, M. Os youtubers mais bem pagos de 2019. Forbes, Brasil, 26 dez. 2019. Disponível em: https://forbes.com.br/listas/2019/12/os-youtubers-mais-bem-pagos-de-2019/. Acesso em: 25 abr. 2020.

BRANCALEONI, A. P. L.; OLIVEIRA, R. R. De. Silêncio! Não desperte os inocentes: sexualidade, gênero e educação sexual a partir da concepção de educadores. Revista IberoAmericana de Estudos em Educação, [s. 1.], v. 10, n. esp. 2, p. 1445-1462, 2015.

BRASIL. Secretaria de Vigilância em saúde. Departamento de DST, Aids e Hepatites Virais. Pesquisa de conhecimento, atitudes e práticas na população brasileira. Brasília: Ministério da Saúde, 2016. 166p.

BRASIL. Secretaria de Vigilância em saúde. Boletim Epidemiológico. Análise epidemiológica da violência sexual contra crianças e adolescentes no Brasil, 2011 a 2017. Brasília. v. 49, n. 27, jun. 2018. 17p. Disponível em:

http://portalms.saude.gov.br/images/pdf/2018/junho/25/2018-024.pdf. Acesso em: 04 out. 2018.

CARNEIRO, R. U. C.; COSTA, M. C. B. Tecnologia e deficiência intelectual: práticas pedagógicas para inclusão digital. Revista on line de Política e Gestão Educacional, [s. 1.], v. 21, n. esp. 1, p. 706-719, 2017. Disponível em:

https://periodicos.fclar.unesp.br/rpge/article/view/10449. Acesso em: 13 maio 2020.

CECARELLO, C. Mídia e sexualidade: benefícios ou malefícios? In: DESIDÉRIO, R. Sexualidade, educação e mídias: novos olhares, novas práticas. Londrina: EDUEL, p. 171179, 2016.

CENTRO REGIONAL DE ESTUDOS PARA O DESENVOLVIMENTO DA SOCIEDADE DA INFORMAÇÃO - Cetic.br. Pesquisa sobre o uso da internet por crianças e adolescentes no Brasil: TIC kids online Brasil/Núcleo de Informação e Coordenação do Ponto BR, [editor]. São Paulo: Comitê Gestor da Internet no Brasil, 2018. Disponível em: https://www.cetic.br/pesquisa/kids-online/publicacoes/. Acesso em: 10 dez. 2019.

COSTA, A. E. B. Modelação In: BANDURA, A.; AZZI, R. G.; POLYDORO, S. (Org.). Teoria social cognitiva: conceitos básicos. Porto Alegre: Artmed, p. 123-148, 2008.

COSTA, L. 'Desafio da rasteira': o youtuber por trás da perigosa brincadeira. Veja, São Paulo, 12 fev. 2020. Disponível em: https://veja.abril.com.br/blog/virou-viral/desafio-darasteira-o-youtuber-por-tras-da-perigosa-brincadeira/. Acesso em: 17 fev. 2020.

COUTO, D. P. Freud, Klein, Lacan e a constituição do sujeito. Revista Psicologia em Pesquisa, [s. 1.], v. 11, n. 1, 2017. Disponível em: 
https://periodicos.ufjf.br/index.php/psicologiaempesquisa/article/view/23388. Acesso em: 08 maio 2020.

ESTADO DE MINAS. Menina morre ao cair e bater a cabeça durante 'desafio' na escola; veja vídeo. Estado de Minas, Belo Hozironte, 12 fev. 2020. Disponível em:

https://www.em.com.br/app/noticia/nacional/2020/02/11/interna_nacional,1121078/menina-

morre-ao-cair-e-bater-a-cabeca-durante-desafio-na-escola-vej.shtml. Acesso em: 15 fev. 2020.

FRUGOLI, A.; JÚNIOR, C. A O. M. A sexualidade na terceira idade na percepção de um grupo de idosas e indicações para a educação sexual. Arquivos de Ciências da Saúde da UNIPAR, [s. 1.], v. 15, n. 1, 2011. Arquivos de Ciências da Saúde da UNIPAR. Disponível em: https://revistas.unipar.br/index.php/saude/article/view/3696. Acesso em 1 maio 2020.

FURLANI, J. Educação sexual: possibilidades didáticas. In: LOURO, G. L.; FELIPE, J.; GOELLNER, S. V. (Orgs.). Corpo, gênero e sexualidade: um debate contemporâneo na educação. Petrópolis, RJ: Vozes, p. 67-82, 2013

GUEDES, W.; VIEIRA, P.; CALAZANS, F. Olá, pessoal, bem-vindos ao meu canal: Youtubers Mirins e a subjetivação da criança na contemporaneidade. In: CONGRESSO BRASILEIRO DE CIÊNCIAS DA COMUNICAÇÃO. 40., 2017. Curitiba. Anais [...]. Curitiba, PR, 2017. Disponível em:

http://www.intercom.org.br/sis/eventos/2017/resumos/R12-2704-1.pdf. Acesso em: 10 jan. 2020.

INSTITUTO NACIONAL DE GEOGRAFIA E ESTATTÍSTÍCA. Pesquisa nacional por amostra de domicílios contínua. Acesso à Internet e à televisão e posse de telefone móvel celular para uso pessoal 2017.2018. 12 p. Disponível em:

https://www.ibge.gov.br/estatisticas/multidominio/condicoes-de-vida-desigualdade-epobreza/17270-pnad-continua.html?edicao=23205\&t=publicacoes. Acesso em: 20 dez 2019.

KARHAWI, I. Influenciadores digitais: conceitos e práticas em discussão. In: CONGRESSO BRASILEIRO CIENTÍFICO DE COMUNICAÇÃO ORGANIZACIONAL E RELAÇÕES PÚBLICAS, 11., 2017 Belo Horizonte. Anais [...]. Belo Horizonte: Abrapcorp, 2017.

Disponível em:

https://editora.pucrs.br/acessolivre/anais/abrapcorp/assets/edicoes/2017/arquivos/15.pdf. Acesso em: 05 out 2018.

KLEINA, N. A história do YouTube, a maior plataforma de vídeos do mundo. Tecmundo, 12 jul. 2017. Disponível em: https://www.tecmundo.com.br/youtube/118500-historia-youtubemaior-plataforma-videos-do-mundo-video.htm. Acesso em: 20 mar. 2020.

L'OFFICIEL. Aos 97 anos, Iris Apfel agora é da mesma agência de Gisele Bündchen. L'OFFICIEL, 31 jan. 2019. Disponível em: https://www.revistalofficiel.com.br/popculture/aos-97-anos-iris-apfel-agora-e-da-mesma-agencia-de-gisele-bundchen. Acesso em: 01 maio 2020.

LEMES, S. S.; MAIA, A. C. B.; REIS-YAMAUTI, V. L. Educação sexual na modalidade ead: um estudo exploratório. Revista on line de Política e Gestão Educacional, [s. 1.], n. 18, p. 106-114, 2015. Disponível em: https://periodicos.fclar.unesp.br/rpge/article/view/9378/6229. Acesso em: 10 maio 2020 
MAIA, A. C. B. Orientação sexual na escola: In: RIBEIRO, P. R. M. (Org.). Sexualidade e educação: aproximações necessárias. São Paulo: Arte \& Ciência, p. 153-179, 2004.

MAIA, A. C. B.; RIBEIRO, P. R. M. Educação sexual: princípios para ação. Doxa: Revista Brasileira de Psicologia e Educação, Araraquara, v. 15, n. 1, p. 75-84, 2011.

MAIA, A. C. B. et al. Educação sexual para pessoas com deficiência física. Revista IberoAmericana de Estudos em Educação, Araraquara, v. 10, n. 1, p. 215-224, 2015. DOI: https://doi.org/10.21723/riaee.v10i1.7775. Acesso em: 13 maio 2020.

MARQUES, P. C. P.; BORGES, J. J. S. Educomunicação: origens e conexões de uma nova área de conhecimento. In: CONGRESSO NACIONAL DE EDUCAÇÃO, 3., 2016. Natal. Anais [...]. Natal, RN, 2016. Disponível em: http://www.editorarealize.com.br/revistas/conedu/trabalhos/TRABALHO_EV056_MD1_SA1 9_ID9 436_16082016200111.pdf. Acesso em: 08 maio 2020.

MONTEIRO, S. A. S.; STORTO, J. L. Educação infantil: uma reflexão plural da história e da sexualidade. Revista Ibero-Americana de Estudos em Educação, Araraquara, v. 14, n. 1, p. 1982-5587, 2019. Disponível em:

https://periodicos.fclar.unesp.br/iberoamericana/article/view/11865. Acesso em: 12 maio 2020.

MOTA, B. S..; BITTENCOURT, M.; VIANA, P. M. F. A influência de Youtubers no processo de decisão dos espectadores: uma análise no segmento de beleza, games e ideologia. E-Compós, Brasília, v. 17, n. 3, set./dez. 2014. Disponível em: https://www.ecompos.org.br/e-compos/article/view/1013. Acesso em: 01 out. 2018.

ONU. Organização das Nações Unidas. Relatório da Conferência Internacional sobre População e Desenvolvimento. Plataforma de Cairo, 1994. Disponível em: http://www.unfpa.org.br/Arquivos/relatorio-cairo.pdf. Acesso em: 15 jan. 2020.

PACHECO, R. V.; MELO, S. M. M. A influência de filmes da barbie sobre a educação sexual das crianças: na busca da compreensão de professoras sobre o tema. Revista IberoAmericana de Estudos em Educação, v. 9, n. 3, p. 656-667, 2015. Disponível em: https://periodicos.fclar.unesp.br/iberoamericana/article/view/6437. Acesso em: 12 maio 2020.

PRIOSTE, C. O adolescente e a internet: laços e embaraços no mundo virtual. São Paulo: Editora da Universidade de São Paulo, Fapesp, 2016.

REUTERS. Homem que inspirou desafio do balde com gelo morre após batalha contra ELA. Exame, 12 dez. 2019. Disponível em: https://exame.abril.com.br/mundo/homem-queinspirou-desafio-do-balde-com-gelo-morre-apos-batalha-contra-ela/. Acesso em: 20 fev. 2020.

RIBEIRO, P. R. M. Educação sexual para além da informação. São Paulo: EPU,1990.

SANTOS, I. P. A formação de professores na perspectiva da educomunicação. Revista on line de Política e Gestão Educacional, Araraquara, v. 21, n. esp. 1, p. 640-648, 2017. Disponível em: https://periodicos.fclar.unesp.br/rpge/article/download/10031/6800. Acesso 
em: 10 maio 2020.

SILVA, M. C. G.; SANTOS, L. S. Aprendendo a ser menina: publicidade infantil, gênero, e identidade em Youtuber mirim. Revista Educação, Psicologia e Interfaces, v. 3, n. Dossiê Inclusão e Diversidade, p. 52-66, 2019. Disponível em:

https://educacaoepsicologia.emnuvens.com.br/edupsi/article/view/176. Acesso em: 14 abr. 2020.

SOUZA, C. J.; DENARI, F. E.; COSTA, M. P. R. O discurso das pessoas com deficiência física sobre a própria sexualidade. Revista ibero-americana de estudos em educação, [s. 1.], v. 12, n. 4, p. 2177-2192, 2017.

SPAZIANI, R. B.; MAIA, A. C. B. Educação para a sexualidade e prevenção da violência sexual na infância: concepções de professoras. Rev. psicopedag., São Paulo, v. 32, n. 97, p. 61-71, 2015. Disponível em:

http://pepsic.bvsalud.org/scielo.php?script=sci_arttext\&pid=S0103-

84862015000100007\&lng=pt\&nrm=iso. Acesso em: 03 maio 2020.

WESTENBERG, W. The influence of YouTubers on teenagers. An overview of the influence Dutch YouTubers have on their teenage viewers and to what extent this influence is good or bad. University of Twente, The Netherlands, 2016.

YOUTUBE. Youtube para imprensa. 2019. Disponível em:

https://www.youtube.com/intl/pt-BR/yt/about/press/. Acesso em: 15 fev. 2020.

\section{Como referenciar este artigo}

TAVARES, Ronielisson Loiola de Jesus; MESQUITA, Fabiana Elias. Youtubers: potencial de contribuição na educação sexual. Revista on line de Política e Gestão Educacional, Araraquara, v. 24, n. 2, p. 554-570, maio/ago. 2020. e-ISSN:1519-9029. DOI: https://doi.org/10.22633/rpge.v24i2.13692

Submetido em: 10/12/2019

Revisões requeridas: 05/02/2020

Aprovado em: 25/03/2020

Publicado em: 09/04/2020 